\title{
Management of Cancer-associated Thrombosis (CAT): Symptomatic or Incidental
}

\author{
PAVLOS PAPAKOTOULAS ${ }^{1 *}$, NIKOLAOS TSOUKALAS ${ }^{2 *}$, ATHINA CHRISTOPOULOU ${ }^{3}$, \\ ALEXANDROS ARDAVANIS ${ }^{4}$, GEORGIOS KOUMAKIS ${ }^{4}$, CHRISTOS PAPANDREOU $^{5}$, \\ GEORGIOS PAPATSIMPAS ${ }^{6}$, PAVLOS PAPAKOSTAS ${ }^{7}$, GEORGIOS SAMELIS $^{8}$, \\ CHARALAMBOS ANDREADIS ${ }^{1}$, GERASIMOS ARAVANTINOS ${ }^{9}$, NIKOLAOS ZIRAS ${ }^{10}$, \\ CHARALAMBOS KALOFONOS ${ }^{11}$, EPAMEINONDAS SAMANTAS ${ }^{9}$, MARIA SOUGGLERI ${ }^{3}$, \\ PARIS MAKRANTONAKIS ${ }^{12}$, GEORGIOS PENTHEROUDAKIS ${ }^{13}$, ATHANASIOS ATHANASIADIS ${ }^{14}$, \\ HELEN STERGIOU ${ }^{15}$, SOFIA TRIPODAKI ${ }^{4}$, ALEXANDROS BOKAS ${ }^{1}$, ANASTASIOS GRIVAS ${ }^{4}$, \\ ELENI TIMOTHEADOU ${ }^{5}$, EVANGELOS BOURNAKIS ${ }^{16}$, IOANNIS VARTHALITIS ${ }^{17}$ and IOANNIS BOUKOVINAS ${ }^{15}$ \\ ${ }^{I}$ Theagenio Anticancer Hospital, Thessaloniki, Greece; \\ ${ }^{2} 401$ General Military Hospital, Athens, Greece; \\ ${ }^{3}$ Saint Andrew General Hospital, Patras, Greece; \\ ${ }^{4}$ Agios Savvas Anticancer Hospital, Athens, Greece; \\ ${ }^{5}$ Papageorgiou General Hospital, Thessaloniki, Greece; \\ ${ }^{6}$ IASO Thessalias Hospital, Larissa, Greece; \\ ${ }^{7}$ Metropolitan General Hospital, Athens, Greece; \\ ${ }^{8}$ Ippokrateio General Hospital, Athens, Greece; \\ ${ }^{9}$ Agioi Anargyroi Anticancer Hospital, Kifissia, Greece; \\ ${ }^{10}$ Metaxa Anticancer Hospital, Piraeus, Greece; \\ ${ }^{11}$ General Hospital University of Patras, Patras, Greece; \\ ${ }^{12}$ Interbalkan Medical Center, Thessaloniki, Greece; \\ ${ }^{13}$ General Hospital University of Ioannina, Ioannina, Greece; \\ ${ }^{14}$ General Hospital of Larissa, Larissa, Greece; \\ ${ }^{15}$ Bioclinic Hospital, Thessaloniki, Greece; \\ ${ }^{16}$ Aretaieio University Hospital, Athens, Greece; \\ ${ }^{17}$ Errikos Dunant Hospital, Athens, Greece
}

\begin{abstract}
Background: Cancer-associated thrombosis (CAT), the second leading cause of death in patients with cancer can
\end{abstract}

This article is freely accessible online.

*These Authors contributed equally to this study.

On behalf of the Hellenic Society of Medical Oncology (HeSMO), Athens, Greece.

Correspondence to: Dr. Nikolaos Tsoukalas, MD, MSc, Ph.D., Medical Oncologist, MSc in Bioinformatics, Deputy Director at Oncology Department of 401 General Military Hospital, Hellenic Society of Medical Oncology (HeSMO), Athens, Greece. Mob: +30 6977366056, e-mail: tsoukn@yahoo.gr

Key Words: Thrombosis, low molecular weight heparin, LMWH, cancer-associated thrombosis, CAT, incidental CAT, symptomatic CAT. be treated with low molecular weight heparin (LMWH) according to guidelines. Patients and Methods: A multicenter prospective observational study was carried out to record antithrombotic treatment practice, assess thrombosis recurrence and bleeding, and identify potential risk factors. Adult patients from 18 Oncology Departments throughout Greece were followed-up for 12 months. Results: A total of 120 patients with CAT receiving anticoagulant treatment were enrolled (35\% incidental); $85 \%$ were treated for more than 6 months, $95.8 \%$ were treated with tinzaparin and smaller percentages with other agents. Thrombosis recurred in three patients and there was minor bleeding in four patients. Bleeding was associated with high body mass index (>35 $\left.\mathrm{kg} / \mathrm{m}^{2}\right)$, trauma history, renal insufficiency and bevacizumab use. Conclusion: Incidental thrombosis contributes significantly to CAT burden. Long-term use of LMWH seems to be effective and safe. Several risk factors associated with bleeding should be considered during anti-coagulation therapy planning. 
The relationship between thrombosis and cancer was first described more than 150 years ago by Professor Armand Trousseau (1). Thrombotic events comprise venous thromboembolisms (VTEs) [i.e. deep vein thrombosis (DVT) and pulmonary embolism (PE)], and arterial thrombotic events (ATEs). The mechanism of cancer-associated thrombosis (CAT) is different from thrombosis occurring in patients without cancer $(2,3)$. A number of risk factors for both VTE and ATE have been identified, including cancerrelated, treatment-related and patient-related, and various biomarkers play an important role in CAT (4-6). Chemotherapy also increases the risk of CAT $(7,8)$; in particular, platinum-based chemotherapy regimens as well as anti-metabolites significantly increase the risk for thrombotic events (9). There is also evidence that immunomodulatory agents, vascular endothelial growth factor pathway inhibitors, tyrosine kinase inhibitors, and radiotherapy put patients at greater risk for ATEs (7).

It has been estimated that $18 \%$ of patients with cancer develop VTE and receive anticoagulation treatment (10), whereas the reported incidence of ATE in patients with cancer is $1.0-4.7 \%(11,12)$.

Cancer patients who have already experienced CAT are still at high risk for recurrent VTE despite therapeutic anticoagulation (13). Data from trials have shown that this risk rises to $20 \%(14,15)$. From a large cohort of 3,805 patients with cancer with VTE (RIETE registry) (16) a number of risk factors for recurrence were identified. According to these results, patients younger than 65 years old, patients with PE as first event, and patients newly diagnosed ( $<3$ months) with cancer are at higher risk for recurrent VTE (16). Other risk factors identified were: cancer site (brain, lung, myeloproliferative neoplasms or myelodysplastic disorders, ovarian cancer, stage IV pancreatic cancer), cancer stage (advanced or metastatic disease), and histology (adenocarcinoma type) $(17,18)$.

It is well known that there is always a tradeoff between prevention of VTE recurrence and causing bleeding through use of anticoagulation therapy. For instance, patients with immobility, metastatic disease, recent medical history of bleeding and those with creatinine clearance $<30 \mathrm{ml} / \mathrm{min}$, are known to be at increased risk of major bleeding (17). Other factors increasing bleeding risk are associated with high body mass index (BMI) (19), renal insufficiency (20), as well as the dosage of anticoagulation treatment; therefore, a balance between the risk of recurrence of VTE and bleeding should be struck.

The occurrence of CAT does have an impact on a patient's life, since there is an increase in morbidity (21) and mortality. In fact, VTE has been associated with significantly greater mortality, and it is also an early factor in mortality during the first four cycles of outpatient chemotherapy (22). VTE during chemotherapy can significantly reduce progression-free survival and overall survival (23), since it is the second leading cause of death in outpatients with cancer. In addition, it may affect the disease outcome by delaying the treatment or modifying the treatment planning (4) and is associated with a reduction in the patient's quality of life and a significant economic burden (24).

Clinical guidelines for CAT recommend the use of lowmolecular-weight heparin (LMWH) for the initial treatment of established thrombosis in patients with cancer up to 6 months irrespective of the bleeding risk. Recently, specific direct oral anticoagulants (DOACs) have been added to the guidelines for CAT treatment for selected patients with low bleeding risk and no drug-to-drug interaction with applied chemotherapy (25). After this period, the decision for the termination or the continuation of anticoagulation should be based on the clinicians' assessment of the benefit-to-risk ratio, tolerability, patient preference, and cancer activity (26-28). Regarding cancer activity, for patients with active cancer, i.e. locally advanced or metastatic, it is also recommended that they continue anticoagulation indefinitely $(29,30)$.

The prospective observational study The Greek Management of Thrombosis (GMaT) [ClinicalTrials.gov identifier: NCT03292107] in patients with CAT was conducted by the Hellenic Society of Medical Oncology (HeSMO). The aim of the study was to illustrate the clinical practice of Medical Oncologists regarding the use of antithrombotic therapy in patients with cancer. Data were collected in relation to the number of thrombotic episodes, their type, duration and outcome of the antithrombotic therapy. This article describes the results of the study in relation to patients with VTE during the study period.

\section{Patients and Methods}

The present study was a prospective, observational study of adult patients with cancer diagnosed with thrombosis. Participants were recruited from 18 Oncology Departments in Greece, and signed a consent form prior to their inclusion in the study according to the declaration of Helsinki. The study was approved by the Scientific Committees of the participating hospitals. During the baseline visit, demographic, relevant clinical parameters, medical history data related to cancer, treatment and patient were recorded in case report forms. Anticoagulation treatment was administered based on thrombotic events confirmed by imaging techniques (computed tomography/ultrasound triplex). A second visit was scheduled 2 months later to assess incidents of thrombosis recurrence and bleeding events, as well as to evaluate the treatment and the cancer status of the patients. The patients were monitored for 1 year from their enrolment. The effectiveness of anticoagulation treatment was assessed by the number of thrombotic recurrences and its safety by the number of bleeding events recorded. Moreover, correlations between the recurrence of thrombosis and potential risk factors such as gender, BMI, age, smoking status, cancer primary site, metastatic disease, low versus high risk for VTE, chemotherapy agent and specific agents such as bevacizumab, as well as medical history details such as: history of heart failure, renal insufficiency and history of trauma were evaluated. The same correlations were also evaluated in relation to bleeding events. 
The demographic and clinical/prognostic data of the patients at baseline were described by means of numerical summary statistics, i.e. mean \pm standard deviation (SD) or percentages within the various groups. The correlation between categorical variables was tested using chi-square test. The magnitude of the correlation was expressed as odds ratio (OR) with a respective $95 \%$ confidence interval (CI), and when it was not possible to calculate the OR, it was expressed by means of relative risk. For the study parameters expressed in numerical format, such as age, BMI, Khorana score (4), the significance of the difference between groups was tested by means of analysis of variance (ANOVA). The significance level was set to $p<0.05$. The statistical analysis was performed using SPSS v.21 (IBM, Armonk, NY, USA).

\section{Results}

One hundred and twenty patients with cancer who had already experienced thrombosis (incidental or symptomatic) and who used anticoagulation treatment were enrolled in the study. The baseline characteristics of the patients are presented in Table I.

The proportion of males to females was equal (males: $52 \%, p>0.05)$. The mean age of the patients was $63.9 \pm 12.5$ years and their mean BMI was $27.1 \pm 5 \mathrm{~kg} / \mathrm{m}^{2}$.

The majority of the patients had metastatic disease $(80 \%)$, whereas $11 \%$ among them had locally advanced disease $(\mathrm{N}+)$. High-risk for thrombosis chemotherapy agents (HRTCA), such as cisplatin, carboplatin, fluorouracil and gemcitabine, were administered to $74 \%$ of patients, who were mainly treated as outpatients ( $80.2 \%$ of the total population).

Regarding the primary site of cancer (Table I), the majority were in the lung $(20 \%)$, pancreas $(12 \%)$ and colorectum $(13 \%)$. In all types of cancer, metastatic disease ranged from $62.5 \%$ (stomach) to $100 \%$ (breast). Thrombotic events (Table I) were mainly VTEs and only a minority (5\%) were ATEs, while $31 \%$ were PE. The mean duration of treatment was $6.8 \pm 3.8$ months and $85 \%$ of patients received LMWH for more than 6 months.

In a large proportion of patients $(35 \%)$, thrombosis was diagnosed incidentally and treated as symptomatic (mean duration $=5.5 \pm 3.4$ months). A quarter of those patients had lung cancer, $19 \%$ had pancreatic cancer, $17 \%$ had rectal cancer and the remaining patients had cancer at other sites. One patient had a recurrence and a second patient had grade I bleeding.

Concerning the patients' medical history, $16 \%$ already had a history of thrombotic events, 55\% had had some type of surgery in the past and a small percentage had trauma history $(7.5 \%)$ or renal insufficiency $(2.5 \%)$; a large percentage $(28 \%)$ of the patients also had other comorbidities such as cardiological, respiratory or endocrinological issues.

New thrombotic events appeared in three outpatients ( $2.5 \%$ of the studied population) and this was confirmed by means of computed tomography/triplex; of those (see Table II), one patient was symptomatic, two received HRTCAs;
Table I. Baseline characteristics.

\begin{tabular}{|c|c|c|}
\hline Characteristic & & Value \\
\hline \multicolumn{3}{|l|}{ Gender (n, \%) } \\
\hline Male & & $63(52 \%)$ \\
\hline \multicolumn{3}{|l|}{ Age, years } \\
\hline Mean \pm SD & & $63.9 \pm 12.5$ \\
\hline \multicolumn{3}{|l|}{$\mathrm{BMI}, \mathrm{kg} / \mathrm{m}^{2}$} \\
\hline Mean \pm SD & & $27.1 \pm 5$ \\
\hline \multicolumn{3}{|l|}{ Smoking } \\
\hline Current $(\mathrm{N}=115)$ & & $27(23.5 \%)$ \\
\hline \multirow[t]{2}{*}{ History $(\mathrm{N}=93)$} & & $36(38.7 \%)$ \\
\hline & Total & Metastatic \\
\hline \multicolumn{3}{|l|}{ Tumor type (n, \%) } \\
\hline Lung & $24(20 \%)$ & $17(71 \%)$ \\
\hline Pancreas & $14(12 \%)$ & $10(71 \%)$ \\
\hline Colorectal & $16(13 \%)$ & $13(81 \%)$ \\
\hline Breast & $11(9 \%)$ & $11(100 \%)$ \\
\hline Stomach & $8(6.5 \%)$ & $5(62.5 \%)$ \\
\hline Ovarian & $3(2.5 \%)$ & $2(67 \%)$ \\
\hline Bladder & $6(5 \%)$ & $4(67 \%)$ \\
\hline Other & $38(32 \%)$ & $27(71 \%)$ \\
\hline \multicolumn{3}{|l|}{ Stage of disease, n (\%) } \\
\hline Metastatic(M1) (N=112) & & $90(80 \%)$ \\
\hline Locally advanced $(\mathrm{N}+)(\mathrm{N}=112)$ & & $12(11 \%)$ \\
\hline \multicolumn{3}{|l|}{$\begin{array}{l}\text { Type of thrombotic event } \\
\text { at enrollment }(n, \%)\end{array}$} \\
\hline DVT & & $56(51.8 \%)$ \\
\hline $\mathrm{PE}$ & & $33(30.6 \%)$ \\
\hline Visceral & & $13(12.0 \%)$ \\
\hline Arterial & & $6(5.6 \%)$ \\
\hline Incidental & & $42(35 \%)$ \\
\hline \multicolumn{3}{|l|}{ History } \\
\hline Thrombosis & & $20(16 \%)$ \\
\hline Bleeding & & $5(4.2 \%)$ \\
\hline Surgery $(\mathrm{N}=116)$ & & $66(55.0 \%)$ \\
\hline Trauma $(\mathrm{N}=116)$ & & $9(7.5 \%)$ \\
\hline Renal insufficiency & & $3(2.5 \%)$ \\
\hline \multicolumn{3}{|l|}{ Other comorbidities } \\
\hline Cardiological, respiratory, endocrinological & & $34(28 \%)$ \\
\hline \multicolumn{3}{|l|}{ Chemotherapy agents } \\
\hline High risk for thrombosis & & $74(61.7 \%)$ \\
\hline \multicolumn{3}{|l|}{ Anemia/use of ESAs } \\
\hline Hemoglobin $<10 \mathrm{~g} / 1$ & & $19(15.8 \%)$ \\
\hline \multicolumn{3}{|l|}{ Platelet count } \\
\hline$\geq 350 \times 10^{9} / 1$ & & $26(21.7 \%)$ \\
\hline \multicolumn{3}{|l|}{ Leukocyte count } \\
\hline$>11 \times 10^{9} / 1$ & & $19(15.8 \%)$ \\
\hline
\end{tabular}

BMI: Body mass index; SD: standard deviation; DVT: deep vein thrombosis; PE: pulmonary embolism; ESAs: erythropoiesis stimulating agents.

one had metastatic disease and simultaneously had a high BMI $\left(>35 \mathrm{~kg} / \mathrm{m}^{2}\right)$. No significant correlation was found between the recurrence of thrombosis and age (cut off $\leq 65$ years vs. older), gender, high BMI $\left(>35 \mathrm{~kg} / \mathrm{m}^{2}\right)$, smoking status, cancer primary site (high-risk $v s$. other), and 
Table II. Characteristics (potential risk factors) of patients with recurrent thrombosis.

\begin{tabular}{lcccccccccc}
\hline Patient & Gender & $\begin{array}{c}\text { Age, } \\
\text { years }\end{array}$ & $\begin{array}{c}\text { BMI, } \\
\mathrm{kg} / \mathrm{m}^{2}\end{array}$ & $\begin{array}{c}\text { Tumor } \\
\text { type }\end{array}$ & $\begin{array}{c}\text { First } \\
\text { event }\end{array}$ & Metastatic & HRTCA & $\begin{array}{c}\text { Outpatient } \\
\text { Symptomatic } \\
\text { episode }\end{array}$ & $\begin{array}{c}\text { Heart failure } \\
\text { history }\end{array}$ \\
\hline 1 & M & 73 & 26.4 & Lung & DVT & No & Yes & Yes & Yes & Yes \\
2 & F & 88 & 24.1 & Ovarian & DVT and visceral & No & No & Yes & No & No \\
3 & F & 62 & 35.9 & Other* & Visceral VTE & Yes & Yes & Yes & No & No \\
\hline
\end{tabular}

BMI: Body mass index; DVT: deep vein thrombosis; HRTCA: high risk for thrombosis chemotherapy agents; F: female; M: male. *According to Khorana stratification (4).

Table III. Correlation between potential risk factors and a recurrence of thrombosis.

\begin{tabular}{llcr}
\hline Risk factor & & OR $(95 \%$ CI $)$ & $p$-Value \\
\hline Gender & Female $v s$. male & $2.3(0.2-26.0)$ & 0.60 \\
Age & $<65$ Years $v s$. older & $1.8(0.2-20.4)$ & 0.99 \\
BMI & $>35 v s . \leq 35 \mathrm{~kg} / \mathrm{m}^{2}$ & $6.6(0.5-81.2)$ & 0.22 \\
Smoking status & Ever $v s$. never & $1.6(0.1-18.1)$ & $>0.99$ \\
Cancer primary site & High-risk $v s$. other* & $2.3(0.2-26.5)$ & 0.60 \\
Metastatic disease & Yes $v s$. no & $0.1(0.01-1.3)$ & 0.045 \\
Chemotherapy agent & Low risk for VTE $v s$. high risk & $0.7(0.7-7.7)$ & 0.99 \\
History of heart failure & Yes $v s$. no & RR=1.5** & $<0.0001$ \\
\hline
\end{tabular}

BMI: Body mass index; CI: confidence intervaI; OR: odds ratio; RR: relative risk; VTE: venous thrombotic event. *According to Khorana stratification (4).**OR cannot be calculated as none of the patients without recurrent thrombosis had a medical history of heart failure.

chemotherapy agents (Table III). In contrast, patients who had history of heart failure were at higher risk of recurrent thrombosis; in particular, one out of the three patients with recurrent thrombosis had a history of heart failure $(33 \%)$ but none of the patients without recurrent thrombosis had such medical history $(p<0.0001)$. According to the analysis, it seems that metastatic disease had an opposite effect on recurrent thrombosis, as two $(67 \%)$ of these patients had no metastasis, while the percentage of patients without metastases in the non-recurrent group was $18.69 \%(p=0.04)$.

Regarding safety, bleeding events were observed in four patients $(3.3 \%)$, and all the events were minor (grade 1). All these patients had metastatic disease and received HRTCAs, whereas only one had experienced a PE; one of them was hospitalized (Table IV).

Numerous recorded parameters were examined for correlation with bleeding events (Table V). Gender, age (cut off $\leq 65$ years), primary cancer site (high risk $v s$. other as proposed by the Khorana stratification), metastatic disease and the type of chemotherapy were not associated with bleeding $(p \geq 0.05)$. The effect of smoking was marginally associated with bleeding (ever vs. never: $0 / 66=0 \%$ vs. $3 / 52=5.8 \% ; p=0.08$ ).

In contrast, bleeding was found to be correlated with a high BMI $\left(>35 \mathrm{~kg} / \mathrm{m}^{2}\right)$ [OR=13.2, 95\%CI=1.6-106.4), $\left.p<0.05\right]$. In particular, two of the patients with bleeding events had a high BMI, while the percentage of patients with a high BMI who had not experienced bleeding was only $6.9 \%$. Bevacizumab did have an important role in bleeding events $(p<0.0001)$, since all four patients with bleeding events were treated with this agent. However, the percentage of patients who had no bleeding and who were treated with bevacizumab was low $(9.5 \%, 11$ out of 116). Finally, bleeding was highly related to a medical history of both trauma ( $p=0.0013)$ and renal insufficiency $(p=0.0037)$. In particular, two out of the patients with bleeding events had a trauma history, as opposed to $6 \%$ of the patients with a trauma history and no bleeding event; one of the patients with a bleeding event had renal insufficiency, in contrast to two $(1.75 \%)$ patients with such insufficiency who were in the group of patients without bleeding event.

The vast majority of the patients $(95.8 \%)$ were treated with tinzaparin and lower percentages with bemiparin $(1.7 \%)$ and fondaparinux $(2.5 \%)$. Moreover, the vast majority of them received full treatment doses without modification. During the follow-up period, 28 patients $(23 \%)$ died, however, no death was related to thrombosis or treatment with LMWH.

\section{Discussion}

CAT management is challenging due to the risk of recurrent VTE and anticoagulant-related bleeding and there are many pitfalls to avoid $(31,32)$ such us drug interactions, comorbidities, renal or hepatic insufficiency, nausea and 
Table IV. Characteristics (potential risk factor) of patients with bleeding events.

\begin{tabular}{lccccccc}
\hline patient & Tumor type & Age, years & BMI, $\mathrm{kg} / \mathrm{m}^{2}$ & First event & Metastatic & HRTCA & Outpatient \\
\hline 1 & Rectal & 80 & 23.5 & PE & Yes & Yes & Yes \\
2 & Rectal & 80 & 23.5 & DVT & Yes & Yes & Yes \\
3 & Other* & 52 & 37.6 & DVT & Yes & Yes & Yes \\
4 & Other* & 82 & 36.2 & DVT & Yes & Yes & No \\
\hline
\end{tabular}

BMI: Body mass index; HRTCA: high risk for thrombosis chemotherapy agent; PE: pulmonary embolism; DVT: deep vein thrombosis. *According to Khorana stratification (4).

Table V. Association between potential risk factors and bleeding.

\begin{tabular}{llrl}
\hline Risk factor & & OR $(95 \%$ CI $)$ & $p$-Value \\
\hline Gender & Female $v s$. male & $3.6(0.4-34.8)$ & 0.34 \\
Age & $<65$ Years $v s$. older & $2.7(0.3-27.0)$ & 0.62 \\
BMI & $>35$ s. $\leq 35 \mathrm{~kg} / \mathrm{m}^{2}$ & $13.5(1.6-106.4)$ & 0.03 \\
Smoking status & Ever $v s$. never & $0.9(0.9-1.0)$ & 0.08 \\
Cancer primary site & High-risk $v s$. other* & $0.9(0.9-1.0)$ & 0.12 \\
Metastatic disease & Yes $v s$. no & $1.1(1.0-1.1)$ & 0.58 \\
Chemotherapy agent & Low risk for VTE $v s$. high risk & $1.1(1.0-1.1)$ & 0.57 \\
Treatment with bevacizumab & Yes $v s$. no & RR=10.4 (5.9-18.2)** & $<0.0001$ \\
History of trauma & Yes $v s$. no & $15.0(1.8-123.5)$ & 0.0013 \\
History of renal insufficiency & & $18.7(1.3-270.3)$ & 0.0037 \\
\hline
\end{tabular}

BMI: Body mass index; CI: confidence intervaI; OR: odds ratio; RR: relative risk; VTE: venous thrombotic event. *According to Khorana stratification (4). **OR cannot be calculated as all patients who manifested bleeding were treated with bevacizumab.

vomiting, and thrombocytopenia, and these can affect the choice of anticoagulant agent.

Reasons for recurrent thrombosis during anticoagulation therapy include anticoagulant-related causes (noncompliance, temporary stopping of the therapy for surgeries or due to bleeding or thrombocytopenia, or inadequate dosing), cancer-related causes (progression of cancer, inadequately treated cancer, or mechanical compression and venous stasis from nodal involvement), as well as other causes (heparin-induced thrombocytopenia or central venous catheter-related VTE) $(26,29)$.

The present prospective multicenter observational study (GMaT) enrolled 120 patients with cancer who had already suffered a thrombotic event and received anticoagulation treatment. CAT was an incidental finding in 35\% of them. The follow-up period was 12 months. New thrombotic events occurred among three patients $(2.5 \%)$; interestingly, only in one patient was the event symptomatic. No significant association $(p \geq 0.05)$ was found between the recurrence of thrombosis and age, gender, high BMI $\left(>35 \mathrm{~kg} / \mathrm{m}^{2}\right)$, smoking status, primary cancer site and type of chemotherapy (HRTCA vs. non HRTCA). In contrast, recurrent thrombosis was found to be related to non-metastatic disease and a history of heart failure $(p<0.05)$.
There are numerous other studies which have looked at the efficacy of various anti-coagulants on patients with cancer with varying results. In a study comparing DOACs and LMWHs (33), in a cohort of 200 patients without active gastrointestinal tract or urinary tract lesions treated with rivaroxaban, the rate of recurrent VTE was $4.4 \%$ which was no different from the GMaT study $(p=0.5709)$. In larger studies such as the TROPIQUE (prospective observational study) involving 409 patients receiving LMWH (34), the percentage of VTE recurrence was $6.1 \%$ and similarly there was non-statistically significant difference compared to that observed in GMaT (2.5\%, $p=0.1875)$. In contrast, other large studies (35) involving more than two anti-coagulants (DOACs, LMWH and warfarin) report higher VTE recurrence rates within shorter periods (6 months). More specifically, reported recurrence VTE rates were $13.2 \%$ and $17.5 \%$ for patients treated with rivaroxaban $(\mathrm{N}=707)$ and warfarin $(\mathrm{N}=1061)$, respectively, representing a significant higher risk $(p<0.05)$ than in our study. In the CATCH randomized clinical trial (36) that studied tinzaparin versus warfarin for treatment of acute VTE in patients with active cancer, it was found that the 6month cumulative incidence of recurrent VTE was $7.2 \%$ (31 out of the 449 patients treated with tinzaparin). Given the difference of $4.70 \%$ (95\% CI $=-0.43 \%$ to $8.13 \%$ ) it was not 
possible to establish statistical meaning from the GMaT results ( $p=0.0925$ ). In contrast, in the CATCH trial, the cohort treated with warfarin had 451 patients, out of whom 45 had recurrent VTE $(10.5 \%)$, a statistically significant difference of $8.00 \%$ (95\% CI $=2.65-11.77 \%, p<0.0103)$. In the CLOT randomized control trial, 27 out of $336(8.0 \%)$ patients treated with dalteparin and 53 out of 336 patients $(15.6 \%)$ treated with oral anti-coagulant (coumarin for 6 months, initiated by dalteparin for up to 7 days) manifested recurrent thrombosis (15), which suggests there is no difference with the GMaT results for dalteparin $(p=0.0592)$, while the percentage of VTE was higher for those treated with oral anticoagulant $(p=0.0003)$.

In a meta-analysis, following the inclusion of four retrospective and six prospective studies, it was shown that there is a higher risk for recurrent thrombosis in patients $\leq 65$ years old and in patients with metastatic malignancy or lung or gastrointestinal malignancy. In our GMaT study, the mean age of the three patients with recurrent thrombosis was $74 \pm 13$ years compared with patients without recurrent VTE who had a mean age of $64 \pm 12$ years. Moreover, no statistically significant difference was confirmed (ANOVA, $p=0.1301$ ) (18). Notably, the 10 studies included in the metaanalysis reported 331 VTE recurrences in total among 4791 patients, a rate of $6.9 \%$, which is higher than the $2.5 \%$ found in our study $(p=0.0876)$. From our GMaT study, it was concluded that a history of heart failure was risk factor for recurrent thrombosis; according to the literature, heart failure is among the risk factors for VTE (37) irrespective of the existence of cancer. In GMaT, there was no indication for any correlation between the recurrence of thrombosis and metastasis, as well as primary cancer site. By contrast, in literature, recurrent thrombosis was reported to be positively associated with distant metastases (38). However, the number of observed recurrent thrombotic events in GMaT was rather low so we cannot draw any firm conclusions regarding such correlations.

Considering adverse events in GMaT, the bleeding rate was found to be $3.3 \%$ (four patients out of 120). In the TROPIQUE study, among patients administered with LMWH the rate of major bleeding events was $7.0 \%$, and no difference from the GMaT results was shown $(p=0.2054)$ (34). Concerning bleeding events in the CATCH trial, 49 out of $449(10.91 \%)$ patients treated with tinzaparin and 69 out of 451 patients $(15.30 \%)$ treated with warfarin had nonmajor bleeding events (36), while there was a significant reduction in major bleeding $(p=0.004)$ when patients were treated with tinzaparin within the $\mathrm{CATCH}$ environment. In the GMaT study, there were considerably fewer minor bleeding events compared to both approaches $(p<0.05$ in both comparisons). The rates of non-major bleeding events were $8 \%$ and $15 \%$ in the dalteparin and oral anticoagulant groups respectively in the CLOT trial (15); leading to $p=0.1216$ and $p=0.0012$, respectively, compared to the
GMaT results. In summary, GMaT results cannot confirm inferiority or superiority when compared with the results of other studies in relation to LMWH, and showed lower bleeding rates than with oral anticoagulants.

In GMaT, it was found that the bleeding rate was related to a high BMI $\left(>35 \mathrm{~kg} / \mathrm{m}^{2}\right)(\mathrm{OR}=15.14,95 \% \mathrm{CI}=1.85$ 124.15) and this is consistent with other bibliographic reports (19). A history of renal insufficiency was also found to have a role in bleeding effects. A systematic review and metaanalysis of 12 studies (39) in non-cancer patients suffering from renal insufficiency suggests that if patients receive empirically adjusted doses of LMWH, there is no statistically significant difference in bleeding between patients with renal inefficiency and those without $(20,39)$. Especially in relation to tinzaparin (this being the agent for the vast majority of the patients participating in this study), it is well known that it can be used safely at treatment doses, even in elderly patients (40), because there is no accumulation of the peak anti-factor Xa (41). Finally, a history of recent trauma or surgery is one of the factors for increased VTE (37) and in addition it is a risk factor when patients are treated with LMWH (42). Our findings also corroborate this result as the OR for bleeding was approximately 15 for patients with a history of trauma.

The final GMaT outcome related to bleeding indicated that bevacizumab had a role in bleeding events $(p<0.0001)$. The scientific literature findings are rather contradictory: in one study, it was found that bevacizumab did not increase the risk of severe bleeding in patients with cancer who received anticoagulation agents (43); by contrast, in a metaanalysis, this agent was associated with a higher risk of bleeding (44). In GMaT, a correlation for bleeding was found among patients treated with this agent $(R R=10.36,95 \%$ $\mathrm{CI}=5.91-18.17)$.

In this study, all patients were treated with LMWH; nowadays, direct oral anticoagulants have been and continue to be studied for the treatment of VTE for selected cancer populations $(25,45,46)$. However LMWHs are preferred due to pitfalls associated with DOACs, particularly among patients with gastrointestinal cancer (32). From the trials related to DOACs, the HOKUSAI cancer study had a large population of 522 patients initially treated with LMWH and subsequently with oral edoxaban (46). Recurrent VTE occurred in 41 patients $(7.9 \%)$ and major bleeding occurred in 36 patients $(6.9 \%)$. It was not possible to confirm any difference in either recurrent VTE or bleeding from GMaT results ( $p=0.0544$ and $p=0.2026$, respectively). Notably, the HOKUSAI cancer study excluded patients with gastrointestinal or urothelial cancer diagnosed within the previous 6 months, and patients treated with bevacizumab within the previous 6 weeks; since in GMaT these patients were not excluded and considering that all patients with bleeding were treated with bevacizumab and that two patients had colorectal cancer (Table II), there is no proper 
basis for comparison. The SELECT-D randomized control trial, had two arms of 203 patients treated with rivaroxaban and dalteparin respectively, for 6 months. The 6-month recurrence rate for VTE was $4 \%$, while that for major bleeding was $6 \%$ (47). As was the case with the HOKUSAI study, GMaT results did not confirm statistically significant superiority or inferiority $(p>0.05)$. Notably, the GMaT study had a 12-month follow-up, thus again there is no basis for comparison.

The recommended duration of LMWH for CAT is up to 6 months, whereas the continuation of treatment is a clinical decision related to a patient's potential risk factors for the recurrence of thrombosis or bleeding. According to the TiCAT study, it is safe to use tinzaparin beyond 6 months in patients with CAT (reported bleeding risk $0.9 \%$ and $0.5 \%$ per patient and month for months 1-6 and 7-12 respectively, $p=0.5$ ) (48). From a large population-based cohort study, it has been shown that in the absence of anticoagulation therapy, 35 additional deaths from recurrent VTE and six fewer deaths from bleeding would have occurred (17), suggesting that the use of LMWH may prevent more deaths than it causes more bleedings. In GMaT, $85 \%$ of patients received LMWH for more than 6 months with no major bleeding or death related to recurrent thrombosis.

The present study may have some drawbacks; by design it was a multicenter observational pragmatic study, and thus it cannot provide the same level of evidence as randomized controlled clinical trials. In addition, the real-world data collection approach is reflected in the rather limited number of cases of patients with recurrent thrombosis or those who manifested bleeding; thus, statistical tests between patients with events and patients without events cannot always confirm a correlation as is possible by larger studies. Moreover, there were certain situations where not all the data were simultaneously available for all the patients, so parts of the statistical analysis may not have shown correlations which are reported in other scientific research. In contrast, one of the strengths of the GMaT study is the duration of follow-up (12 months), which ensures that the findings reported are accurate for a long-term period. What is more, there was no modification of the anti-coagulation treatment dose.

In conclusion, incidental thrombosis contributes significantly to the burden of CAT and patients with CAT received LMWH for a period longer than 6 months. The longterm use of LMWH seems to be effective and safe as the thrombosis recurrence rate and the number of bleeding events was considerably low and not fatal. A potential risk factor associated with the recurrence of thrombosis was a medical history of heart failure, whereas bleeding events were associated with a high BMI, a medical history of trauma or renal insufficiency, and treatment with bevacizumab. Finally, other factors can complicate anti-coagulation therapy planning, including and not being limited to: drug interactions, comorbidities, such as renal or hepatic insufficiency or dysfunction, nausea and vomiting, or thrombocytopenia, and these can limit the choice of anticoagulant agent.

\section{Conflicts of Interest}

All Authors declare that no competing interests exist regarding this study.

\section{Authors' Contributions}

HeSMO: Conceived the study design, performed the data collection, quality control and analysis; all Authors: contributed to data acquisition, revised and accepted the final manuscript; Dr P. Papakotoulas: wrote the article; Dr N. Tsoukalas: wrote the protocol and coordinated the study.

\section{References}

1 Sheth RA, Niekamp A, Quencer KB, Shamoun F, Knuttinen MG, Naidu $S$ and Oklu R: Thrombosis in cancer patients: Etiology, incidence, and management. Cardiovasc Diagn Ther 7(Suppl 3): S178-S185, 2017. PMID: 29399521. DOI: $10.21037 /$ cdt.2017.11.02

2 Mukai M and Oka T: Mechanism and management of cancerassociated thrombosis. J Cardiol 72(2): 89-93, 2018. PMID: 29588087. DOI: $10.1016 /$ j.jjcc.2018.02.011

3 Schwartz JD and Simantov R: Thrombosis and malignancy: Pathogenesis and prevention. In Vivo 12(6): 619-624, 1998. PMID: 9891224.

4 Khorana AA, Kuderer NM, Culakova E, Lyman GH and Francis $\mathrm{CW}$ : Development and validation of a predictive model for chemotherapy-associated thrombosis. Blood 111(10): 4902-4907, 2008. PMID: 18216292. DOI: 10.1182/blood-2007-10-116327

5 Canale ML, Bisceglia I, Lestuzzi C, Parrini I and Force AC-OT: Arterial thrombosis in cancer: Spotlight on the neglected vessels. Anticancer Res 39(9): 4619-4625, 2019. PMID: 31519559. DOI: 10.21873/anticanres. 13642

6 Lambert M, Ploquin A, Declerck L, Duhamel A, Makhloufi S, Turpin A, Truant S and Hebbar M: Deep vein thrombosis: An independent poor prognosis factor of advanced pancreatic adenocarcinoma. Anticancer Res 36(10): 5527-5530, 2016. PMID: 27798925. DOI: 10.21873/anticanres.11135

7 Aronson D and Brenner B: Arterial thrombosis and cancer. Thromb Res 164 Suppl 1: S23-S28, 2018. PMID: 29703480. DOI: $10.1016 /$ j.thromres.2018.01.003

8 Nishiofuku H, Tanaka T, Anai H, Sueyoshi S, Maeda S, Masada T and Kichikawa K: Hepatic arterial thrombosis: A critical complication during combination therapy of arterial chemoinfusion and sorafenib. Anticancer Res 32(9): 4121-4124, 2012. PMID: 22993371.

9 Barni S, Labianca R, Agnelli G, Bonizzoni E, Verso M, Mandala M, Brighenti M, Petrelli F, Bianchini C, Perrone T and Gasparini G: Chemotherapy-associated thromboembolic risk in cancer outpatients and effect of nadroparin thromboprophylaxis: Results of a retrospective analysis of the Protecht study. J Transl Med 9: 179, 2011. PMID: 22013950. DOI: 10.1186/1479-5876-9-179

10 Smith JD, Baillie J, Baglin T, Griffiths GO, Casbard A, Cohen D, Fitzmaurice DA, Hood K, Rose P, Cohen AT, Johnson M, Maraveyas A, Bell J, Toone H, Nelson A and Noble SI: A 
feasibility study to inform the design of a randomized controlled trial to identify the most clinically and cost effective anticoagulation length with low-molecular-weight heparin in the treatment of cancer-associated thrombosis (ALICAT): Study protocol for a mixed-methods study. Trials 15: 122, 2014. PMID: 24726032. DOI: 10.1186/1745-6215-15-122

11 Zamorano JL, Lancellotti P, Rodriguez Munoz D, Aboyans V, Asteggiano R, Galderisi M, Habib G, Lenihan DJ, Lip GYH, Lyon AR, Lopez Fernandez T, Mohty D, Piepoli MF, Tamargo J, Torbicki A, Suter TM and Group ESCSD: 2016 ESC position paper on cancer treatments and cardiovascular toxicity developed under the auspices of the ESC Committee for Practice Guidelines: The Task Force for Cancer Treatments and Cardiovascular Toxicity of the European Society of Cardiology (ESC). Eur Heart J 37(36): 2768-2801, 2016. PMID: 27567406. DOI: $10.1093 /$ eurheartj/ehw211

12 Navi BB, Reiner AS, Kamel H, Iadecola C, Okin PM, Elkind MSV, Panageas KS and DeAngelis LM: Risk of arterial thromboembolism in patients with cancer. J Am Coll Cardiol 70(8): 926-938, 2017. PMID: 28818202. DOI: 10.1016/ j.jacc.2017.06.047

13 Piran S and Schulman S: Management of recurrent venous thromboembolism in patients with cancer: A review. Thromb Res 164(Suppl 1): S172-S177, 2018. PMID: 29703478. DOI: 10.1016/j.thromres.2017.12.019

14 Prandoni P, Lensing AW, Piccioli A, Bernardi E, Simioni P, Girolami B, Marchiori A, Sabbion P, Prins MH, Noventa F and Girolami A: Recurrent venous thromboembolism and bleeding complications during anticoagulant treatment in patients with cancer and venous thrombosis. Blood 100(10): 3484-3488, 2002. PMID: 12393647. DOI: 10.1182/blood-2002-01-0108

15 Lee AY, Levine MN, Baker RI, Bowden C, Kakkar AK, Prins M, Rickles FR, Julian JA, Haley S, Kovacs MJ and Gent M: Randomized comparison of low-molecular-weight heparin versus oral anticoagulant therapy for the prevention of recurrent venous thromboembolism in patients with cancer I: Lowmolecular-weight heparin versus a coumarin for the prevention of recurrent venous thromboembolism in patients with cancer. $\mathrm{N}$ Engl J Med 349(2): 146-153, 2003. PMID: 12853587. DOI: 10.1056/NEJMoa025313

16 Trujillo-Santos J, Nieto JA, Tiberio G, Piccioli A, Di Micco P, Prandoni P, Monreal M and Registry R: Predicting recurrences or major bleeding in cancer patients with venous thromboembolism. Findings from the RIETE Registry. Thromb Haemost 100(3): 435439, 2008. PMID: 18766259.

17 Chee CE, Ashrani AA, Marks RS, Petterson TM, Bailey KR, Melton LJ, 3rd and Heit JA: Predictors of venous thromboembolism recurrence and bleeding among active cancer patients: A populationbased cohort study. Blood 123(25): 3972-3978, 2014. PMID: 24782507. DOI: 10.1182/blood-2014-01-549733

18 Louzada ML, Majeed H, Dao V and Wells PS: Risk of recurrent venous thromboembolism according to malignancy characteristics in patients with cancer-associated thrombosis: A systematic review of observational and intervention studies. Blood Coagul Fibrinolysis 22(2): 86-91, 2011. PMID: 21245746. DOI: 10.1097/MBC.0b013e328341f030

19 Mount G, Kovacs MJ, Lazo-Langner A, Siqueira L and Louzada ML: Safety of weight-adjusted dosing of LMWH in clinically obese cancer patients with venous thromboembolism. Blood 128(22): 882-882, 2016. DOI: 10.1182/blood.V128.22.882.882
20 Lutz J, Jurk K and Schinzel H: Direct oral anticoagulants in patients with chronic kidney disease: Patient selection and special considerations. Int J Nephrol Renovasc Dis 10: 135-143, 2017. PMID: 28652799. DOI: 10.2147/IJNRD.S105771

21 Khorana AA, Francis CW, Culakova E, Kuderer NM and Lyman GH: Thromboembolism is a leading cause of death in cancer patients receiving outpatient chemotherapy. J Thromb Haemost 5(3): 632-634, 2007. PMID: 17319909. DOI: 10.1111/j.15387836.2007.02374.x

22 Kuderer NM, Culakova E, Lyman GH, Francis C, Falanga A and Khorana AA: A validated risk score for venous thromboembolism is predictive of cancer progression and mortality. Oncologist 21(7): 861-867, 2016. PMID: 27125754. DOI: $10.1634 /$ theoncologist.2015-0361

23 Mandala M, Reni M, Cascinu S, Barni S, Floriani I, Cereda S, Berardi R, Mosconi S, Torri V and Labianca R: Venous thromboembolism predicts poor prognosis in irresectable pancreatic cancer patients. Ann Oncol 18(10): 1660-1665, 2007. PMID: 1766049. DOI: 10.1093/annonc/mdm284

24 Kourlaba G, Relakis J, Mylonas C, Kapaki V, Kontodimas S, Holm MV and Maniadakis N: The humanistic and economic burden of venous thromboembolism in cancer patients: A systematic review. Blood Coagul Fibrinolysis 26(1): 13-31, 2015. PMID: 25202884. DOI: 10.1097/MBC.0000000000000193

25 Khorana AA, Noble S, Lee AYY, Soff G, Meyer G, O'Connell $\mathrm{C}$ and Carrier M: Role of direct oral anticoagulants in the treatment of cancer-associated venous thromboembolism: Guidance from the SSC of the ISTH. J Thromb Haemost 16(9): 1891-1894, 2018. PMID: 30027649. DOI: 10.1111/jth.14219

26 Kearon C, Akl EA, Ornelas J, Blaivas A, Jimenez D, Bounameaux H, Huisman M, King CS, Morris TA, Sood N, Stevens SM, Vintch JRE, Wells P, Woller SC and Moores L: Antithrombotic therapy for VTE disease: Chest guideline and Expert Panel report. Chest 149(2): 315-352, 2016. PMID: 26867832. DOI: 10.1016/j.chest.2015.11.026

27 Farge D, Bounameaux H, Brenner B, Cajfinger F, Debourdeau P, Khorana AA, Pabinger I, Solymoss S, Douketis J and Kakkar A: International clinical practice guidelines including guidance for direct oral anticoagulants in the treatment and prophylaxis of venous thromboembolism in patients with cancer. Lancet Oncol 17(10): e452-e466, 2016. DOI: 10.1016/S1470-2045 (16)30369-2

28 Khorana AA, Streiff MB, Farge D, Mandala M, Debourdeau P, Cajfinger F, Marty M, Falanga A and Lyman GH: Venous thromboembolism prophylaxis and treatment in cancer: A consensus statement of major guidelines panels and call to action. J Clin Oncol 27(29): 4919-4926, 2009. PMID: 19720907. DOI: $10.1200 / J C O .2009 .22 .3214$

29 Lyman GH, Khorana AA, Falanga A, Clarke-Pearson D, Flowers C, Jahanzeb M, Kakkar A, Kuderer NM, Levine MN, Liebman H, Mendelson D, Raskob G, Somerfield MR, Thodiyil P, Trent D, Francis CW and American Society of Clinical O: American Society of Clinical Oncology Guideline: Recommendations for venous thromboembolism prophylaxis and treatment in patients with cancer. J Clin Oncol 25(34): 5490-5505, 2007. PMID: 17968019. DOI: $10.1200 / J C O .2007 .14 .1283$

30 Mandala M, Labianca R and European Society for Medical O: Venous thromboembolism (VTE) in cancer patients. ESMO clinical recommendations for prevention and management. Thromb Res 125 Suppl 2: S117-119, 2010. PMID: 20433989. DOI: $10.1016 /$ S0049-3848 (10)70028-1 
31 Frenkel EP and Bick R: Issues of thrombosis and hemorrhagic events in patients with cancer. In Vivo 12(6): 625-628, 1998 PMID: 9891225.

32 Patel HK and Khorana AA: Anticoagulation in cancer patients: A summary of pitfalls to avoid. Curr Oncol Rep 21(2): 18, 2019. PMID: 30715628. DOI: 10.1007/s11912-019-0767-5

33 Mantha S, Laube E, Miao Y, Sarasohn DM, Parameswaran R, Stefanik S, Brar G, Samedy P, Wills J, Harnicar S and Soff GA: Safe and effective use of rivaroxaban for treatment of cancerassociated venous thromboembolic disease: A prospective cohort study. J Thromb Thrombolysis 43(2): 166-171, 2017. PMID: 27696084. DOI: 10.1007/s11239-016-1429-1

34 Cajfinger F, Debourdeau P, Lamblin A, Benatar V, Falvo N, Benhamou Y, Sevestre MA, Farge-Bancel D and Investigators T: Low-molecular-weight heparins for cancer-associated thrombosis: Adherence to clinical practice guidelines and patient perception in tropique, a 409-patient prospective observational study. Thromb Res 144: 85-92, 2016. PMID: 27318244. DOI: 10.1016/j.thromres.2016.06.005

35 Streiff MB, Milentijevic D, McCrae K, Yannicelli D, Fortier J, Nelson WW, Laliberte F, Crivera C, Lefebvre P, Schein J and Khorana AA: Effectiveness and safety of anticoagulants for the treatment of venous thromboembolism in patients with cancer. Am J Hematol 93(5): 664-671, 2018. PMID: 29396864. DOI: 10.1002/ajh.25059

36 Lee AYY, Kamphuisen PW, Meyer G, Bauersachs R, Janas MS, Jarner MF, Khorana AA and Investigators C: Tinzaparin vs. warfarin for treatment of acute venous thromboembolism in patients with active cancer: A randomized clinical trial. JAMA 314(7): 677-686, 2015. PMID: 26284719. DOI: 10.1001/jama.2015.9243

$37 \mathrm{Kim}$ V and Spandorfer J: Epidemiology of venous thromboembolic disease. Emerg Med Clin North Am 19(4): 839-859, 2001. PMID: 11762274. DOI: 10.1016/s0733-8627(05)70221-2

38 Louzada ML, Carrier M, Lazo-Langner A, Dao V, Kovacs MJ, Ramsay TO, Rodger MA, Zhang J, Lee AY, Meyer G and Wells PS: Development of a clinical prediction rule for risk stratification of recurrent venous thromboembolism in patients with cancerassociated venous thromboembolism. Circulation 126 (4): 448-454, 2012. PMID: 22679142. DOI: $10.1161 /$ CIRCULATIONAHA 111.051920

39 Lim W: Low-molecular-weight heparin in patients with chronic renal insufficiency. Intern Emerg Med 3(4): 319-323, 2008. DOI: 10.1007/s11739-008-0164-9

40 Pautas E, Gouin I, Bellot O, Andreux JP and Siguret V: Safety profile of tinzaparin administered once daily at a standard curative dose in two hundred very elderly patients. Drug Saf 25(10): 725-733, 2002. PMID: 18563531. DOI: 10.2165/ 00002018-200225100-00005
41 Siguret V, Gouin-Thibault I, Pautas E and Leizorovicz A: No accumulation of the peak anti-factor Xa activity of tinzaparin in elderly patients with moderate-to-severe renal impairment: The Iris substudy. J Thromb Haemost 9(10): 1966-1972, 2011. PMID: 21819539. DOI: 10.1111/j.1538-7836.2011.04458.x

42 Nieuwenhuis HK, Albada J, Banga JD and Sixma JJ: Identification of risk factors for bleeding during treatment of acute venous thromboembolism with heparin or low-molecularweight heparin. Blood 78(9): 2337-2343, 1991. PMID: 1657248.

43 Leighl NB, Bennouna J, Yi J, Moore N, Hambleton J and Hurwitz H: Bleeding events in bevacizumab-treated cancer patients who received full-dose anticoagulation and remained on study. Br J Cancer 104(3): 413-418, 2011. PMID: 21245868. DOI: $10.1038 /$ sj.bjc. 6606074

44 Ranpura V, Hapani S and Wu S: Treatment-related mortality with bevacizumab in cancer patients: A meta-analysis. JAMA 305(5): 487-494, 2011. PMID: 21285426. DOI: 10.1001/jama.2011.51

45 Fiorelli EM, Rossi RE and GrAm: Edoxaban for the treatment of cancer associated venous thromboembolism as an alternative to low-molecular-weight heparin. Intern Emerg Med 13(7): 1089-1091, 2018. PMID: 29948831. DOI: 10.1007/s11739-0181886-y

46 Raskob GE, van Es N, Verhamme P, Carrier M, Di Nisio M, Garcia D, Grosso MA, Kakkar AK, Kovacs MJ, Mercuri MF, Meyer G, Segers A, Shi M, Wang TF, Yeo E, Zhang G, Zwicker JI, Weitz JI, Buller HR and Hokusai VTECI: Edoxaban for the treatment of cancer-associated venous thromboembolism. N Engl J Med 378(7): 615-624, 2018. PMID: 29231094. DOI: 10.1056/NEJMoa1711948

47 Young AM, Marshall A, Thirlwall J, Chapman O, Lokare A, Hill C, Hale D, Dunn JA, Lyman GH, Hutchinson C, MacCallum P, Kakkar A, Hobbs FDR, Petrou S, Dale J, Poole CJ, Maraveyas $\mathrm{A}$ and Levine M: Comparison of an oral factor Xa inhibitor with low molecular weight heparin in patients with cancer with venous thromboembolism: Results of a randomized trial (SELECT-D). J Clin Oncol 36(20): 2017-2023, 2018. PMID: 29746227. DOI: $10.1200 / J C O .2018 .78 .8034$

48 Jara-Palomares L, Solier-Lopez A, Elias-Hernandez T, AsensioCruz M, Blasco-Esquivias I, Marin-Barrera L, de la BorbollaArtacho MR, Praena-Fernandez JM, Montero-Romero E, NavarroHerrero S, Serrano-Gotarredona MP, Sanchez-Diaz JM, Palacios $\mathrm{C}$ and Otero R: Tinzaparin in cancer-associated thrombosis beyond 6months: TICAT study. Thromb Res 157: 90-96, 2017. PMID: 28719850. DOI: 10.1016/j.thromres.2017.07.004

Received November 5, 2019

Revised November 20, 2019

Accepted November 25, 2019 